\title{
O EM FAVOR DO INVÁLIDO, DE LÍSIAS INTRODUÇÃO, TRADUÇÃO E NOTAS ${ }^{1}$
}

\author{
André Rodrigues Bertacchi*
}

Recebido em 03/02/2018

Aprovado em 05/05/2018

A Constituição dos Atenienses atribuída a Aristóteles informa-nos de uma $l i^{2}$ permitindo aos incapacitados por alguma deficiência de trabalhar e de, por consequência, garantir sua subsistência requisitar da pólis uma pensão. Esta consistia numa alocação diária de dois óbolos e poderia ser concedida somente àqueles que possuíssem um patrimônio menor que três minas. Ao Conselho cabia a realização do exame anual confirmando que o pleiteante cumpria as condições para percepção do benefício. Como era praxe nesses casos, uma decisão favorável poderia ser contestada por um particular, estabelecendo uma disputa entre o beneficiário e o contestante a ser julgada também pelo Conselho. Esta é a situação a que somos apresentados no discurso Em favor do inválido, de Lísias. ${ }^{3}$

\footnotetext{
${ }^{1}$ Gostaria de agradecer aos pareceristas anônimos e também a Márcio André Lopes Cenzi pela leitura atenta e pelas sugestões.

${ }^{2}$ Const. Aten. XLIX, 4: "O Conselho também realiza o exame dos inválidos. Pois há uma lei ordenando que aqueles cujo patrimônio não ultrapassa três minas e que possuem um corpo de tal forma mutilado que não lhes possibilite o exercício de um ofício, depois do exame do Conselho, recebam

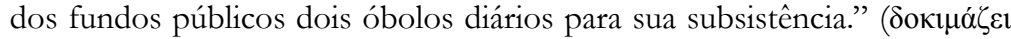

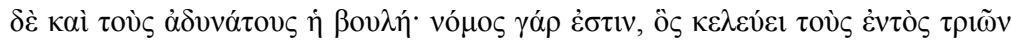

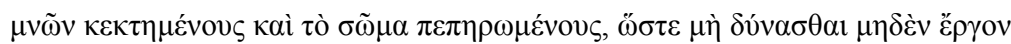

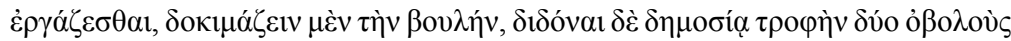
$\dot{\varepsilon} \kappa \alpha ́ \sigma \tau \omega \tau \eta \tilde{\varsigma} \dot{\eta} \mu \varepsilon \dot{\varepsilon} \rho \varsigma_{\text {.) }}$

${ }^{3} \mathrm{O}$ discurso de Lísias e a referida passagem da Constituição dos atenienses são os únicos documentos a atestar a existência, na Atenas democrática, de uma pensão destinada aos inválidos, de modo que dúvidas ainda persistem quanto a esse benefício. As décadas a separar a composição desses textos consistem na primeira dificuldade a tratar da questão, uma vez que Em favor do inválido provavelmente data do final do séc. V e início do séc. IV a.C., enquanto que os especialistas geralmente concordam que o tratado tenha sido escrito não
}

* Doutorando do Programa de PósGraduação em Letras Clássicas, Universidade de São Paulo. Bolsista da Coordenação de Aperfeiçoamento de Pessoal de Nível Superior, CAPES. andre.bertacchi@ gmail.com

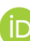




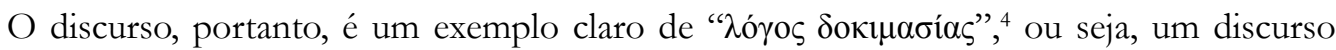

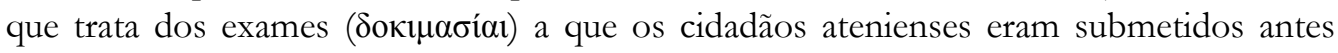
de assumirem um cargo público ou receberem um benefício da pólis, como no caso do presente texto de Lísias. ${ }^{5}$

Quanto às circunstâncias específicas do litígio, o discurso não nos fornece muitas indicações. Não conhecemos o nome das pessoas envolvidas, e em geral são poucas as informações a seu respeito: o orador se identifica como um pequeno artesão, já com certa idade, cuja deficiência o obriga a se servir de duas bengalas para poder se locomover; quanto a seu adversário, só podemos inferir que se trata de um homem mais jovem e mais rico que o cliente de Lísias. Segundo o inválido, não teria havido contato entre os adversários antes da instauração do litígio, o processo tendo sido causado pela inveja do acusador (2), não havendo um desagravo anterior que teria contribuído para a instauração do processo.

Tal fato se faria sentir pela ausência da parte do discurso que a teorização retórica

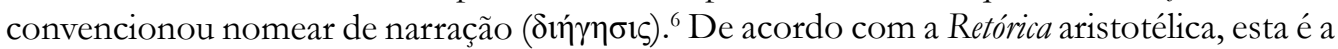
parte em que "se deve relatar as coisas de que trata o discurso"; sua função seria apresentar, de acordo com a perspectiva do orador, as circunstâncias do caso em debate, algo importante sobretudo no gênero judiciário, no qual os juízes tratam de questões que lhes são alheias. ${ }^{8}$ As referências do Em favor do inválido às circunstâncias prévias à instauração do processo,

muito depois da morte de Aristóteles em 332 a.C (muitos comentadores propõem que a autoria do tratado se deve não a Aristóteles, mas a um de seus alunos). Dessa forma, ambos os testemunhos podem retratar um estado de coisas diferente, o que responderia pelas discordâncias entre os dois textos, no valor da pensão, por exemplo, que a Constituição dos atenienses estabelece em dois óbolos, enquanto que o cliente de Lísias diz receber da pólis a metade dessa quantia (26).

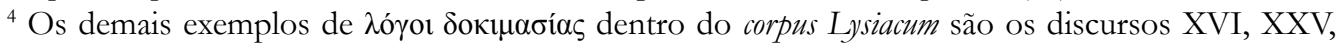
XXVI e XXXI.

${ }^{5}$ O título sob o qual um dos principais manuscritos nos transmite o discurso ("Discurso de defesa frente a acusação pública quanto a negar ao inválido a pensão"; vd. nota 16 abaixo) sugere a

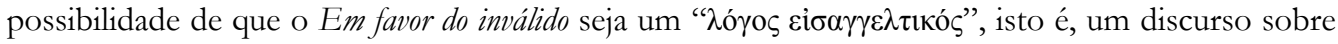

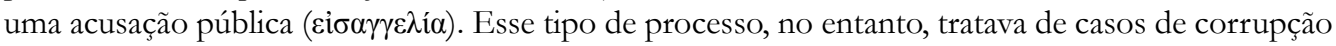
ou traição dos magistrados, e é pouco provável que uma questão tão prosaica quanto a disputa por

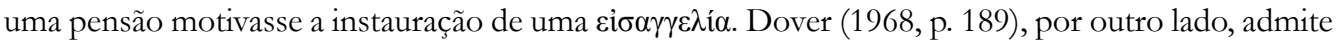
a possibilidade de o discurso ter sido apresentado por ocasião de uma "cỉ $\alpha \alpha \gamma \varepsilon \lambda \lambda^{i} \alpha$ ", citando dois casos em que esse dispositivo teria sido utilizado na disputa por pequenas somas de dinheiro (Hipérides Em favor de Euxenipo passim e Contra Demóstenes 26). Ambos os exemplos, porém, datam do séc. IV

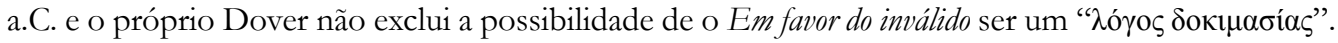
Para maiores detalhes sobre esse procedimento legal, $v d$. Hansen 2009, p. 258-59.

${ }^{6}$ Embora Usher classifique os parágrafos 5-6 do Em favor do inválido como uma narrativa,ele pontua que ela é "totalmente inadequada" (1999, p. 107).

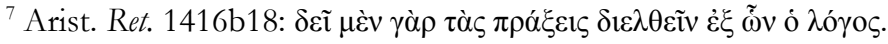

${ }^{8}$ Em contrapartida, os discursos demonstrativos prescindiram da narração (Arist. Ret. 1414a37-b1), uma vez que eles tratam questões de interesse comum e que dizem respeito também aos juízes (Arist. Ret. 1354b), não sendo necessário lhes informar das circunstâncias prévias ao processo.

Classica, v. 31, n. 1, p. 139-149, 2018 
porém, são breves e insuficientes, quando não contraditórias, tampouco estão concentradas em uma passagem específica, mas se encontram dispersas ao longo de todo o texto.

Já no que diz respeito à argumentação, o Em favor do inválido também se destaca pela ausência daquilo que a Retórica aristotélica denomina provas inartificiais (á $\tau \varepsilon \chi v o ı ~ \pi i ́ \sigma \tau \varepsilon ı \varsigma)$, ou seja, aqueles elementos externos ao discurso, os fatos inerentes ao caso os quais o orador deve abordar na defesa de sua posição. ${ }^{9}$ Essa falta é sobretudo relevante no que diz respeito

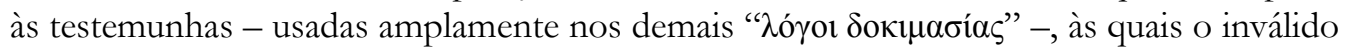
poderia recorrer para confirmar suas afirmações de que é um homem pobre e de que necessita da pensão para sua subsistência.

O discurso, ao contrário, emprega uma técnica argumentativa centrada em provar a inverossimilhança ou incoerência de cada um dos ataques de seu adversário, em um uso paradigmático do que a teorização retórica coetânea denominou de prova por cikós. Consistia a prova por "Eikós" em uma afirmação geral que tivesse a concordância de todas as pessoas, por exemplo, a de que, em um briga entre um homem forte e um fraco, teria sido o primeiro o responsável pelo confronto. O emprego desse recurso se dava na ausência de provas factuais: desse modo, Aristóteles aconselhava o orador, quando este não dispusesse de testemunhas, a utilizar o 'Eikós', dizendo à audiência não pode ser comprado como as testemunhas (1376a17-23). ${ }^{10}$

Tendo em vista tais características do texto, alguns comentadores propuseram a hipótese de que o Em favor do inválido não tivesse sido escrito para ser pronunciado em um litígio realmente discutido no Conselho, mas que se trataria de um discurso fictício, retratando uma situação inventada por Lísias para o divertimento dos seus leitores, à semelhança do Encômio a Helena e a Defesa de Palamedes, de Górgias. Isso motivou Stephen Usher (1999, p.

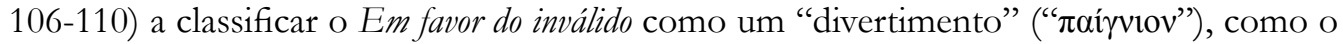
próprio Górgias define seu elogio à rainha espartana. ${ }^{11}$ Ao ler o Em favor do inválido, portanto, estaríamos diante não de um discurso escrito por encomenda para ser pronunciado por um particular em um espaço público, mas de um exercício de composição tratando de um caso fictício, cujo objetivo seria, além de exibir a habilidade retórica do autor, divertir os leitores. A corroborar esta hipótese, Dionísio de Halicarnasso nos informa que a obra de Lísias comportava, além das peças judiciárias pelas quais o autor ficou mais conhecido, "discursos epistolares, sobre cortesãs e outros, que escreveu como divertimento", ${ }^{12}$ e o Em favor do inválido pertenceria a essa categoria.

\footnotetext{
9 Arist. Ret. 1355b35-37: "tudo aquilo que não é provido pelo orador, mas preexiste ao discurso"

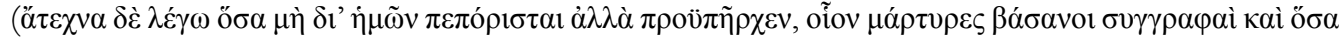
$\tau$ oเaṽ $\alpha$ ). Segundo Aristóteles, são cinco os tipos de provas inartificiais, a saber: leis, testemunhas, contratos, tortura e juramentos (1375a22-1377b).

${ }^{10}$ Para maiores detalhes sobre a prova por દikós, vd. Gagarin, 1994.

${ }^{11}$ Górg. Enc. Hel. 21: "Quis escrever este discurso como um elogio a Helena e como um divertimento

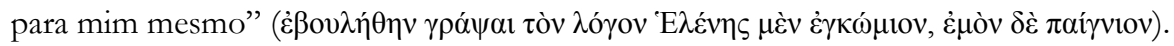

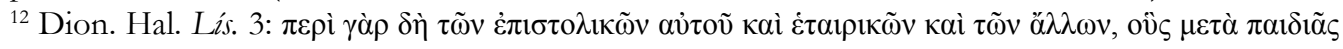

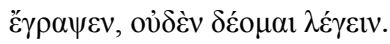


Tal interpretação estaria de acordo com a relativa falta de informação que o orador nos fornece sobre si próprio e as circunstâncias envolvendo seu caso, além de resolver algumas outras dificuldades que o texto apresenta. Se o Em favor do inválido de fato for um discurso fictício, por exemplo, resolve-se a contradição, apontada por alguns comentadores, ${ }^{13}$ entre a declarada pobreza do orador e a encomenda do discurso a um profissional requisitado como Lísias, cujos altos preços não seriam acessíveis a um pobre artífice, como o inválido afirma ser.

Mais importante ainda, o fato de o Em favor do inválido ser um discurso fictício explicaria o uso que o texto faz do humor. Encontramos exemplos de paródia e farsa desde o início do texto, como, por exemplo, no anúncio de que o processo forneceria ao orador uma oportunidade para expor seu modo de vida (1), o que caberia a um jovem ambicioso tentando assumir uma posição de destaque na estrutura política de Atenas, e não a um pobre e velho artífice acometido por uma deficiência. ${ }^{14}$ Esse elemento cômico do Em favor do inválido, uma das características que destacam o discurso dentro da obra de Lísias, serve de argumento em favor da tese de se tratar o texto de uma peça fictícia, uma vez que o austero ambiente dos tribunais desencorajava o uso do humor pelos oradores, sendo raros, fora do presente texto, exemplos do uso do humor por discursos judiciários.

Quanto à data, falta-nos a notícia de gramáticos antigos e a única indicação temporal contida no texto permite-nos apenas localizá-lo entre 403 a.C., data do governo dos trinta, mencionado no parágrafo 25 do discurso, e 380, data da morte de Lísias.

Para o texto grego utilizado na tradução, consultamos a edição de Carey (Lysiae 2007) e de Chiron (Lysias 2015), mas não nos servimos de nenhum deles como texto base, apresentando divergências em passagens significativas. O texto que reproduzimos a seguir, portanto, pode ser considerado inédito, ainda que pesadamente devedor do aparato crítico de Carey e dos comentários de Chiron. Nas notas, procuramos expor nossas escolhas textuais nas passagens mais problemáticas, além de esclarecer brevemente referências obscuras do texto, que podem dificultar sua fruição por um leitor moderno. ${ }^{15}$

\footnotetext{
${ }^{13}$ Por exemplo, Chiron in Lysias 2015, p. 142.

${ }^{14}$ Como nota Usher (1999, p. 109).

$15 \mathrm{O}$ mais importante manuscrito para o estabelecimento do texto do Em favor do inválido é o Palatinus Graecus 88, designado pela sigla X, datado do séc. XII/XIII, correntemente na Biblioteca da Universidade em Heidelberg. Trata-se da fonte primária não só deste, mas também do restante dos discursos numerados de 3-31 do Corpus Lysiacum (para mais informações, vd. Lysiae 2007, p. xiii-xviii). Dentro da tradição derivada desse manuscrito, destaca-se, no que se refere ao texto do Em favor do inválido, o Ambrosianus Graecus 436 (Af, segundo a designação de Avezzù, seguida por Carey), códice datado do séc. XV, e o Marcianus Graecus VIII.1 (coll. 1159), também do séc. XV. Supõe-se que ambos são herdeiros intermediários de $\mathrm{X}$, não sendo conhecida nenhuma cópia direta do manuscrito. Tampouco há indícios que nos permitam pressupor a existência de uma fonte alternativa, hoje perdida, para o texto de Lísias, de modo que as divergências entre os códices consistem ou em correção ou em erro do escriba. Não se conhece nenhum papiro contendo o Em favor do inválido.
} 


\section{$<$ YMEP TOY A $\triangle$ YNATOY >}

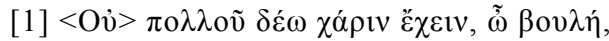

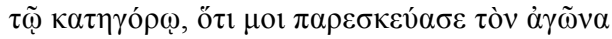

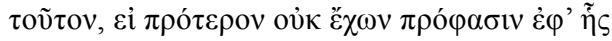

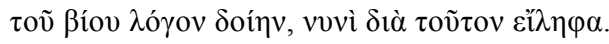

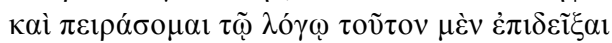

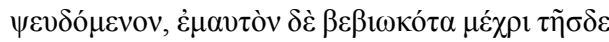

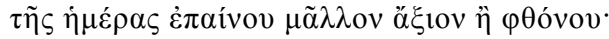

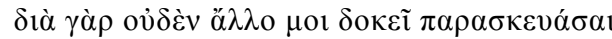

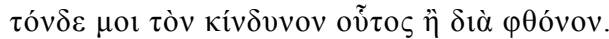

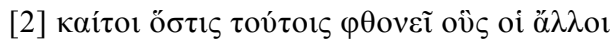

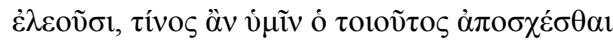

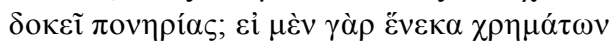

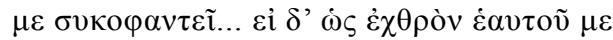

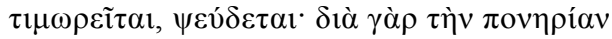

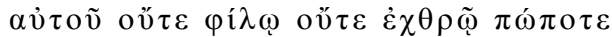

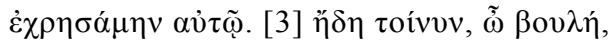

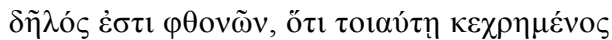

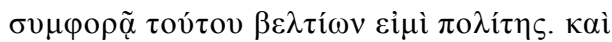
$\gamma \grave{\alpha} \rho$ oĩ $\mu \alpha \imath \delta \varepsilon \tilde{\imath} v, \tilde{\omega} \beta o v \lambda \eta ́, \tau \grave{\alpha} \tau o \tilde{v} \sigma \omega ́ \mu \alpha \tau o \varsigma$

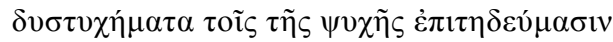

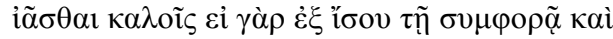

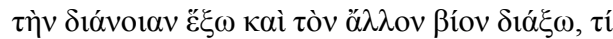

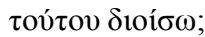

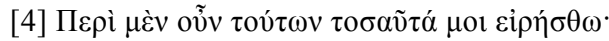

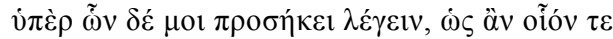

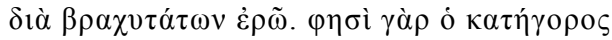

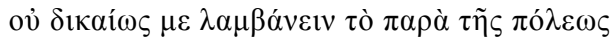

\section{XXIV - Em favor do inválido ${ }^{16}$}

[1] Não estou longe de ser grato ao meu acusador, membros do Conselho, por me ter envolvido neste litígio; se nunca antes tive um pretexto para explicar meu modo de vida, agora eu consegui um. E tentarei mostrar em meu discurso que este homem mente e que, até o presente dia, tenho vivido de modo a merecer elogios, e não a ser invejado. Pois, julgo eu, por nenhum outro motivo senão por inveja esse homem me ameaça. [2] Ora, quem inveja aqueles de que os demais se apiedam, de que vileza vós julgais que um homem desse tipo se absteria? Pois, se ele me denuncia por causa de meu dinheiro... ${ }^{17}$ mas se ele procura se vingar de mim como se eu fosse seu inimigo, ele mente. Pois, por causa de sua vileza, nunca o tive nem como amigo nem como inimigo. [3] Já está claro, membros do Conselho, que ele tem inveja de mim, porque eu, mesmo sofrendo dessa grave enfermidade, sou um cidadão melhor do que ele. Com efeito, eu penso que os infortúnios do corpo devem ser curados pelos belos ${ }^{18}$ hábitos da alma. Pois, se meu pensamento e todo restante de meu modo de vida for igual à minha desgraça, em que eu me distinguo desse homem?

[4] A esse respeito basta o que eu já disse; sobre o que convém falar em minha defesa, o farei com a maior brevidade possível. Diz meu acusador que injustamente recebo dinheiro da cidade.

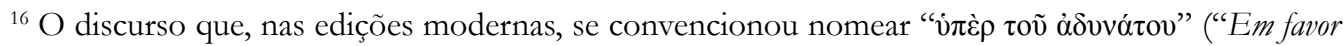
do inválido", a partir de Gernet e Bizos in Lysias 1926) nos é transmitido pelo Palatinus Graecus 88

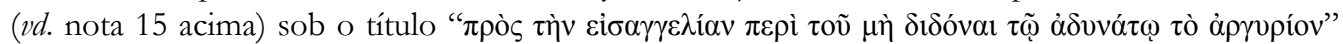
("Discurso de defesa frente a acusação pública quanto a negar ao inválido a pensão"); Harpocrácio,

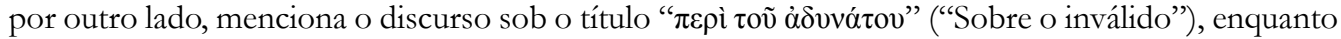

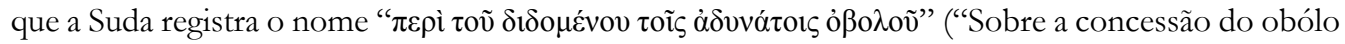

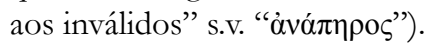

${ }^{17}$ A frase termina com um silêncio abrupto, modo de surpreender os leitores e também de expressar o absurdo da proposição inicial. O público então deveria suprir a proposição inicial com uma conclusão como "seria absurdo". Não seria, portanto, necessária a emenda do texto, proposta por Sauppe, para

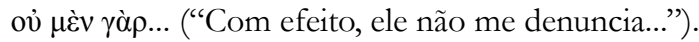

${ }^{18}$ Os manuscritos contêm $\kappa \alpha \lambda \tilde{\omega} \varsigma$, lição mantida por Carey, mas é difícil adaptar esse advérbio ao

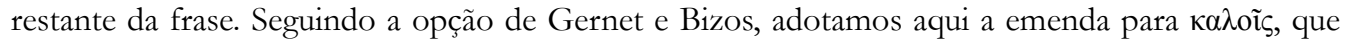
pode ser explicada por uma má leitura do copista do ditongo "oı".
} 


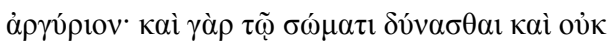

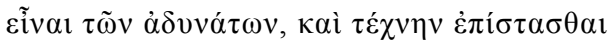

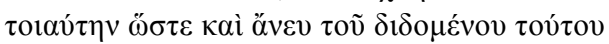

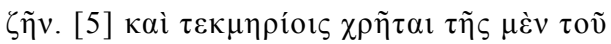

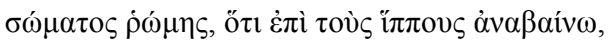

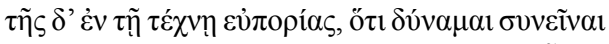

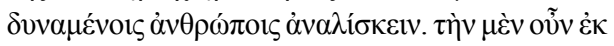

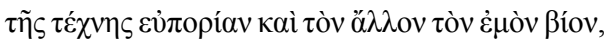

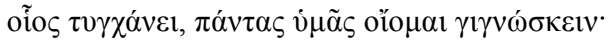

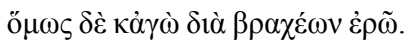

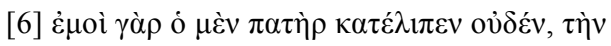

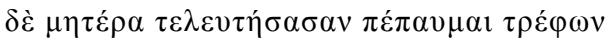

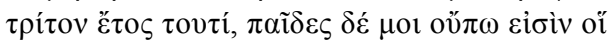
$\mu \varepsilon \theta \varepsilon \rho \alpha \pi \varepsilon v ́ \sigma o v \sigma 1 . \tau \dot{\varepsilon} \chi v \eta \nu \delta \dot{\varepsilon} \kappa \varepsilon ́ \kappa \tau \eta \mu \alpha 1 \beta \rho \alpha \chi \dot{\varepsilon} \alpha$

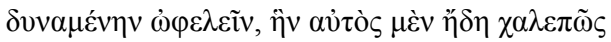

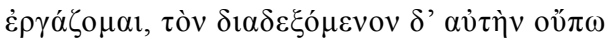

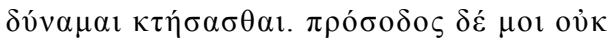

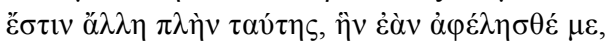

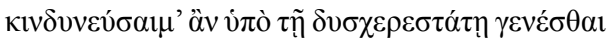

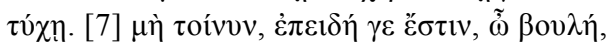

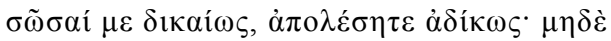

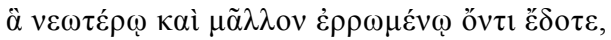

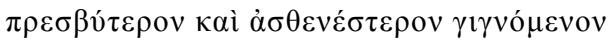

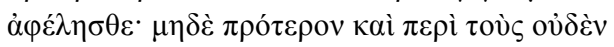

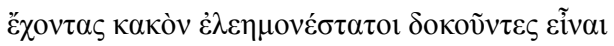

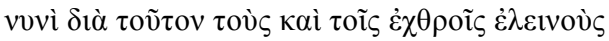

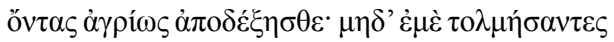

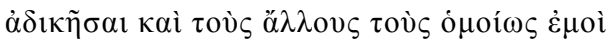

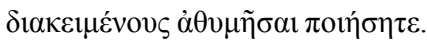

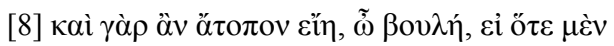

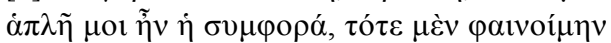

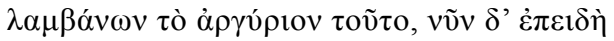

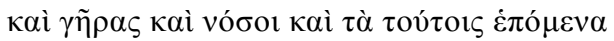

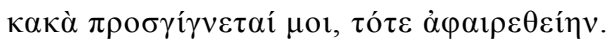

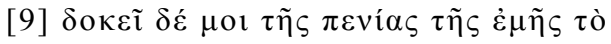

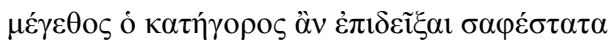

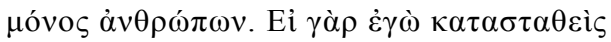
$\chi 0 \rho \eta \gamma$ ò $\varsigma \rho \alpha \gamma \omega \delta$ o $\varsigma \varsigma \pi \rho \circ \kappa \alpha \lambda \varepsilon \sigma \alpha i ́ \mu \eta v$
Com efeito, afirma ele tanto que eu tenho um corpo saudável e não pertenço à categoria dos inválidos quanto que eu exerço um ofício tal que me permitiria viver sem a percepção dessa quantia. [5] E apresenta como prova de minha força corporal o fato de eu ser capaz de montar um cavalo e do meu sucesso como artífice, que eu posso me reunir com pessoas que podem despender grandes somas. Quanto ao sucesso advindo de meu ofício e o restante de minha vida, penso que todos vós os conheceis; não obstante, falarei brevemente sobre eles: [6] não recebi nenhuma herança de meu pai, deixei de me ocupar de minha mãe com sua morte, dois anos atrás, e ainda não tenho filhos que cuidem de mim; possuo um ofício que pode me trazer poucos benefícios, e eu próprio já o exerço com dificuldade e ainda não sou capaz de transmiti-lo a um aprendiz; não possuo outra fonte de renda senão esta - se vós a tirásseis de mim, eu correria o risco de me ver lançado ao mais penoso infortúnio.

[7] Então, ó membros do Conselho, já que é possível com justiça me salvar, não me arruineis injustamente; o que me concedestes quando eu era mais jovem e robusto, não me despojeis disso agora que estou mais velho e fraco. Tampouco, já que no passado decidistes agir com o máximo de piedade para os que não sofriam nenhum mal, sejais, por causa desse homem, cruéis com aqueles que inspiram compaixão até mesmo em seus inimigos, nem desencorajeis os que estão em condição semelhante à minha, atrevendo-se a agir injustamente comigo.

[8] Com efeito, seria absurdo, membros do Conselho, se, sofrendo apenas dessa enfermidade, eu - é manifesto a todos - tivesse recebido esse dinheiro, mas agora, quando a ela se soma também a velhice, a doença e os males que as acompanham, eu fosse privado de minha pensão. [9] Julgo que não há ninguém mais apto que meu acusador para deixar clara a extensão de minha penúria: pois se eu, caso fosse designado corego nas competições trágicas, ${ }^{19}$ o intimasse

\footnotetext{
${ }^{19}$ Consistia a khorégía na instrução do coro trágico ou cômico realizada por um particular. Tratavase de uma das liturgias, despesas públicas cujo pagamento a pólis incumbia aos cidadãos mais ricos (e, em alguns casos, também os metecos mais abastados). Para maiores detalhes, vd. Const. Aten. 56.
} 


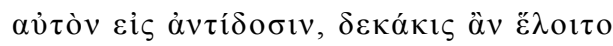

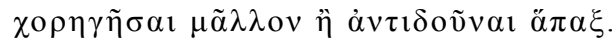

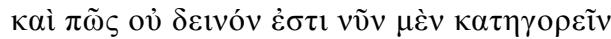

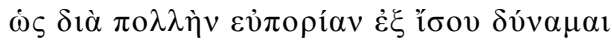

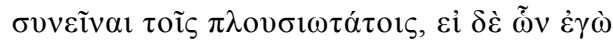

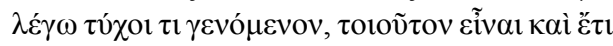
$\pi \varepsilon v \varepsilon \dot{\sigma} \sigma \varepsilon \rho \circ$;

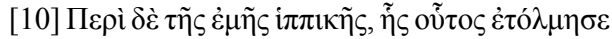

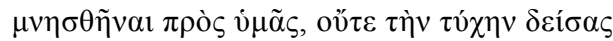

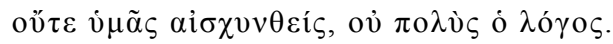

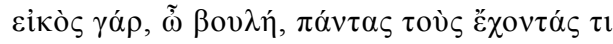

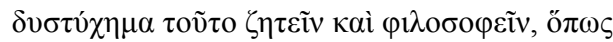

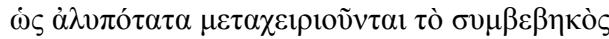

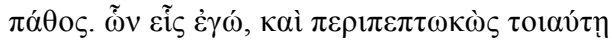

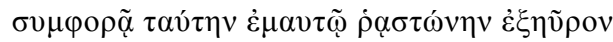

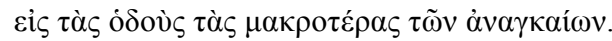

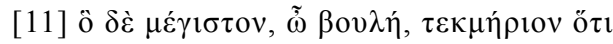

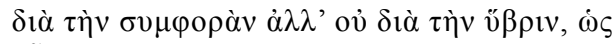

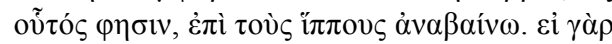

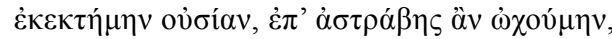

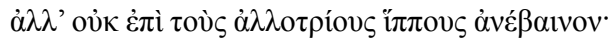

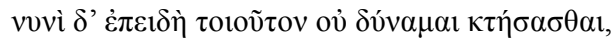

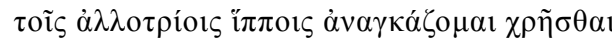
$\pi \mathrm{o} \lambda \lambda \dot{\alpha} \kappa ı \varsigma$. em um processo de antídose, ${ }^{20}$ ele preferiria dez vezes se encarregar do coro do que trocar uma única vez sua fortuna comigo. $\mathrm{E}$ como não seria terrível agora me acusar de poder, por causa de meu grande sucesso, me encontrar com os mais ricos em pé de igualdade, mas, se alguma das coisas de que falo acontecesse, diria que sou assim e ainda mais pobre do que agora? ${ }^{21}$

[10] Sobre minha habilidade com cavalos, que ele se atreve a mencionar perante vós, sem temer a fortuna nem se envergonhar diante de vós, não é preciso falar muitas coisas: é razoável, ${ }^{22}$ membros do Conselho, que todos que sofrem de algum infortúnio investiguem e reflitam o modo menos doloroso de se lidar com o mal que sobre eles se abateu. Sou um desses homens, e, tendo sido acometido por tal desgraça, encontrei uma maneira de tornar mais fáceis os percursos mais longos que sou obrigado a fazer. [11] Mas a maior prova, membros do conselho, de que foi minha desgraça, e não a arrogância- como esse homem alega - que me fez montar a cavalo é fácil de compreender. Pois, se fosse rico, iria sobre uma mula selada, ${ }^{23}$ não montaria cavalos de outrem; mas, porém, já que não me é possível adquirir tal montaria, frequentemente sou forçado a me servir dos cavalos de outros homens.

\begin{abstract}
${ }^{20}$ Um cidadão encarregado de cumprir uma liturgia poderia se eximir da responsabilidade mediante um processo de antídosis - ou troca de propriedade -, transferindo a ônus a outro cidadão, caso provasse que este era mais rico. Originalmente, esse dispositivo previa a troca de propriedade entre dois particulares, mas isso raramente se dava, sendo mais comum que a parte perdedora se incumbisse do pagamento da liturgia. Para maiores detalhes, vd. Isóc. Antid.; Christ 1990.

${ }^{21}$ A última oração, que foi objeto de extensa correção, também apresenta problemas no que se refere ao seu sentido. Preferimos, com Chiron (Lysias 2015), a interpretação de que ela se refere ao orador,

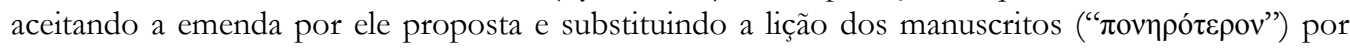
" $\pi \varepsilon v \varepsilon \dot{\sigma} \sigma \varepsilon \rho \circ "$.

${ }^{22}$ Mais uma passagem extensamente emendada. A lição dos manuscritos દ̇ $\gamma \omega ́$ não poderia ser mantida sem o acréscimo de um verbo principal que coordenasse a oração infinitiva (Carey, por exemplo, mantém a correção transmitida por uma família posterior de manuscritos, que completa o texto com

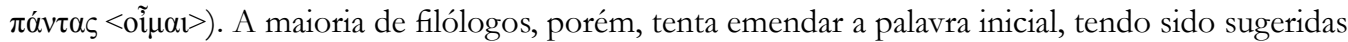

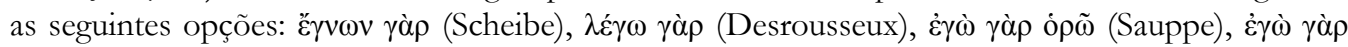

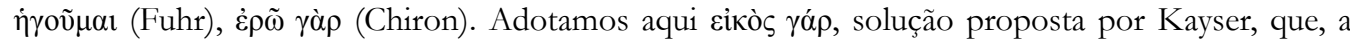
nosso ver, é mais adequada ao sentido da passagem, além de não exigir uma intervenção tão drástica na lição dos manuscritos.
\end{abstract}

${ }^{23}$ A astrábè consistia provavelmente em uma sela com um largo encosto, feita para a montaria de uma mula. 


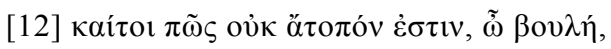

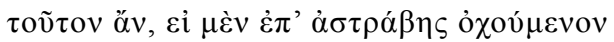

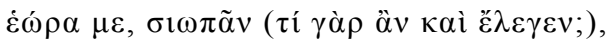

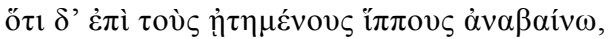

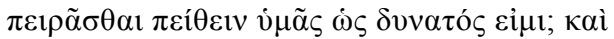

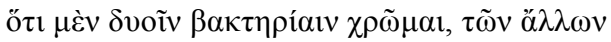

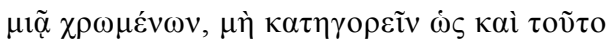

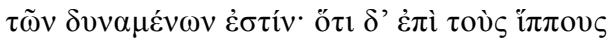

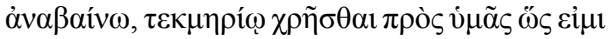

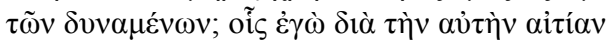
$\dot{\alpha} \mu \varphi о \tau \dot{\varepsilon} \rho 01 \varsigma \chi \rho \tilde{\omega} \mu \alpha 1$.

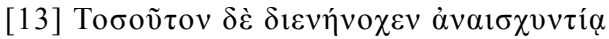

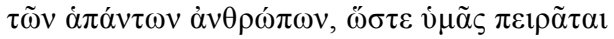

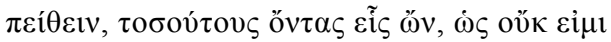

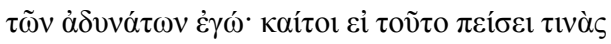

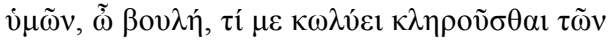

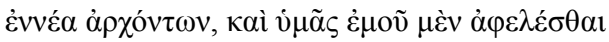

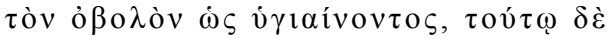

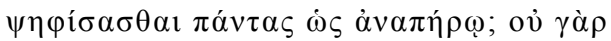

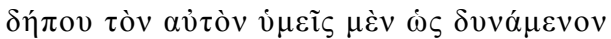
$\dot{\alpha} \varphi \alpha \imath \rho \eta ́ \sigma \varepsilon \sigma \theta \varepsilon$ ¿̀ $\delta 1 \delta$ ó $\mu \varepsilon v o v$, oi $\delta \grave{\varepsilon} \dot{\omega} \varsigma$

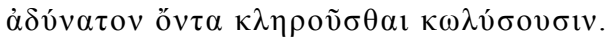

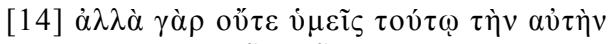

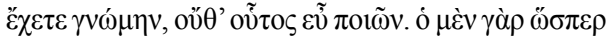

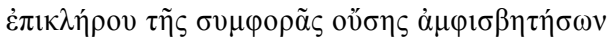

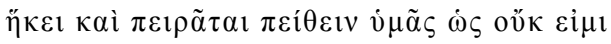

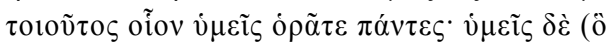

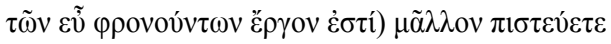

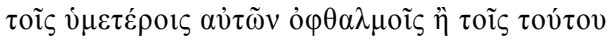
$\lambda$ óyols.

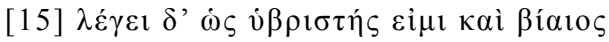
$\kappa \alpha i ̀ ~ \lambda i ́ \alpha v \dot{\alpha} \sigma \varepsilon \lambda \gamma \tilde{\omega} \varsigma \delta 1 \alpha \kappa \varepsilon \dot{\mu} \mu \varepsilon v o \varsigma$, $\varphi \circ \beta \varepsilon \rho \tilde{\omega} \varsigma$ òvo $\mu \alpha \dot{\alpha} \sigma \varepsilon \varepsilon \varepsilon, \mu \varepsilon \dot{\varepsilon} \lambda \lambda \omega v \dot{\alpha} \lambda \eta \theta \tilde{\eta} \lambda \dot{\varepsilon} \gamma \varepsilon ı v$,

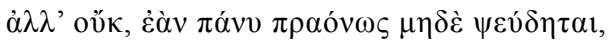

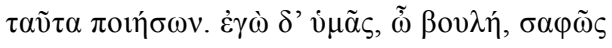

[12] Ora, não é algo absurdo, membros do Conselho: esse homem, se tivesse me visto andando sobre a sela de uma mula, manter-se-ia calado? (pois o que teria para falar?) Mas, porque eu monto cavalos emprestados, tenta persuadir-vos de que sou capaz... Que eu monte cavalos vos serve de prova de que eu pertenço à categoria dos homens capazes? Por que então, já que eu me sirvo de dois bastões, enquanto que os demais precisam só de um, não me acusa ele de pertencer à categoria dos homens capazes? Pela mesma razão me sirvo de ambas coisas. ${ }^{24}$

[13] Tanto ele supera todos os demais homens na imprudência que tenta convencer-vos - mesmo estando só e vós sendo tantos - de que não pertenço à categoria dos inválidos. Contudo, se ele persuadir alguns dentre vós disso, membros do conselho, o que me impede de participar do sorteio dos nove arcontes? O que vos impede de me tirar a pensão como se eu fosse saudável, mas a todos vós de votar o benefício para ele por sua enfermidade? Pois sem dúvida, suspeito, vós irieis destituir um homem da pensão a pretexto de ser capaz, mas a este mesmo os tesmotetas ${ }^{25}$ não permitiriam a participação no sorteio por ser inválido. [14] Mas, não obstante, nem vós tendes a mesma opinião que ele, nem ele tampouco, e faz bem. ${ }^{26}$ Com efeito, ele vem me contestar como se minha desgraça fosse igual a de uma herdeira ${ }^{27}$ e tenta persuadi-los de que não sou como todos vós vedes; mas vós - é o que fazem as pessoas sensatas - confiais mais em vossos próprios olhos do que em suas palavras.

[15] Diz ele que sou insolente, violento e tenho um comportamento excessivamente temerário, como se, utilizando palavras ameaçadoras, dissesse a verdade, mas não fizesse isso, se se expressasse muito calmamente sem mentir. Eu, porém, creio ser

\footnotetext{
${ }^{24}$ Isto é, por ser inválido, ele se serve de um cavalo e de duas bengalas.

${ }^{25}$ Magistrados responsáveis pela aprovação dos sorteados para o arcontado (Arist. Const. Aten. 4). O texto transmitido pelos manuscritos contém somente um genérico oi $\delta \dot{c} . .$. ("eles"), mas não há necessidade de suplementar o original com com ö $\rho \chi 0 v \tau \varepsilon \varsigma$ ou supor uma lacuna no texto.

${ }^{26}$ Consideramos desnecessária a adição de $<\dot{v} \mu \mathrm{i} v>$ antes de $\varepsilon v \tilde{~} \pi$ oı $\tilde{v} v$, defendida por alguns filólogos, que expressaria a discordância do adversário para com os membros do Conselho. Ao contrário, pensamos ser aceitável, e mais de acordo com o texto, a leitura dos manuscritos, indicando a autocontradição das declarações do adversário.

${ }^{27}$ Ou seja, a órfã de um homem sem descendência masculina, que se tornava alvo do cortejo de um grande número de homens, que esperavam angariar para si o patrimônio deixado pelo pai da jovem.
} 


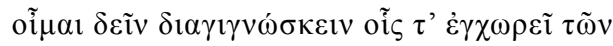

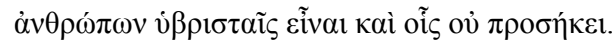

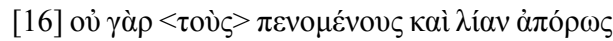

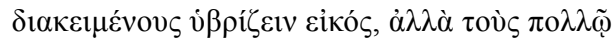

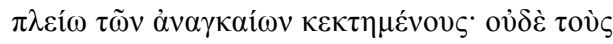

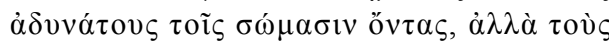

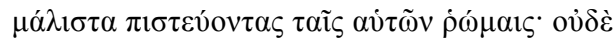

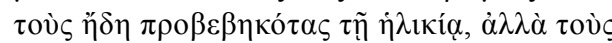

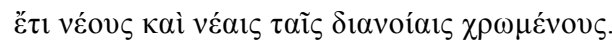

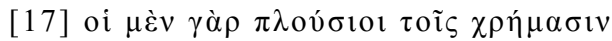

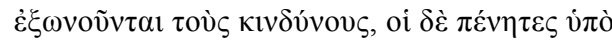

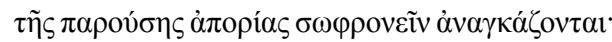

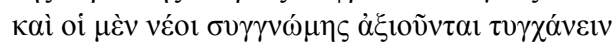

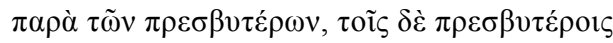

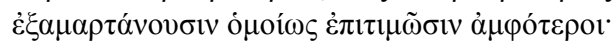

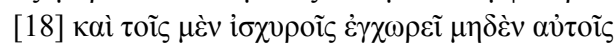
$\pi \alpha ́ \sigma \chi 0 v \sigma ı v$, oū

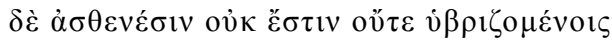

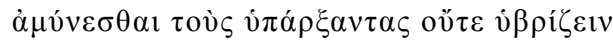

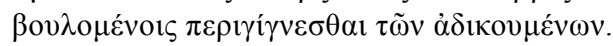

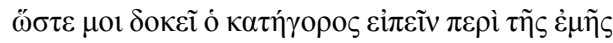

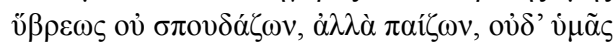

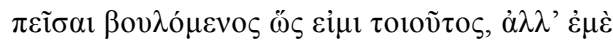

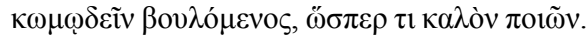

[19] 'E

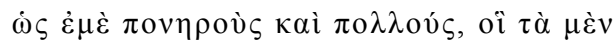
$\dot{\varepsilon} \alpha v \tau \tilde{\omega} \nu \dot{\alpha} v \eta \lambda \omega ́ \kappa \alpha \sigma 1, \tau$ o $\varsigma_{\varsigma} \delta \grave{\varepsilon} \tau \grave{\alpha} \sigma \varphi \dot{\varepsilon} \tau \varepsilon \rho \alpha$

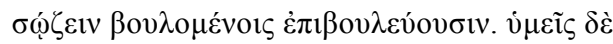

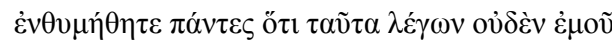

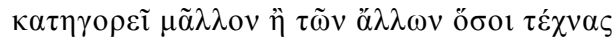

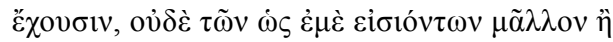

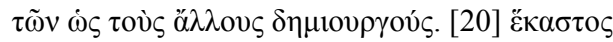

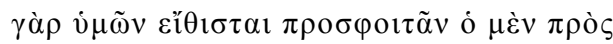

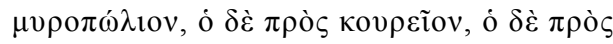

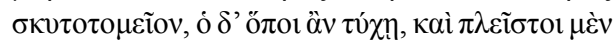

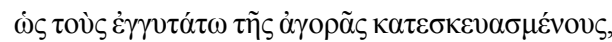

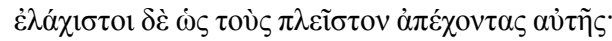

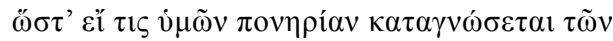

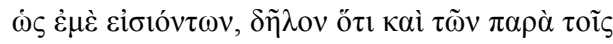

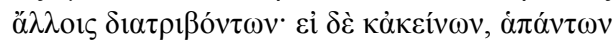

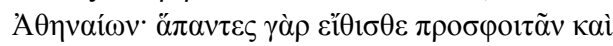

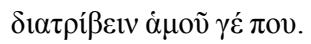

vosso dever distinguir claramente a quais homens se deve permitir ser insolente e quais se deve negálo. [16] Pois não é razoável considerar insolentes aqueles que são pobres e que se encontram em uma situação demasiado difícil, mas quem possui muito mais do que necessita, nem os aflitos por uma deficiência corporal, mas os que têm plena confiança em sua força física, tampouco os já de idade avançada, mas os que ainda são jovens e que pensam de modo juvenil. [17] Os ricos, com efeito, podem pagar, com suas riquezas, para se livrarem do que os ameaça, mas os pobres são forçados a serem prudentes; e se julga que os jovens merecem ser perdoados pelos mais velhos, mas ambos igualmente condenam os mais velhos, quando esses erram. [18] E os fortes podem se permitir o abuso de quem quiserem, mesmo sem sofrerem nenhum mal, mas aos fracos, quando vítimas de abuso, nem lhes é possível se defender dos ofensores, nem, se querem cometer algum abuso, dominar suas vítimas. De modo que julgo que meu acusador não fala sério ao se referir à minha insolência, mas está a brincar, nem quer ele vos persuadir que sou insolente, mas quer zombar de mim, fazendo um gracejo.

[19] Diz ele ainda que sou frequentado por muitos homens sem valor, que dilapidaram seus próprios bens, mas que censuram quem deseja poupar seu patrimônio. Mas todos vós deveis ter em mente que, falando isso, ele não me acusa mais do que todos os demais que praticam um ofício, tampouco os que me procuram mais do que os demais artífices. [20] Pois cada um de vós costuma acorrer um à perfumaria, outro à barbearia, outro à sapataria, outro a qualquer outro lugar, a maioria desses artífices estando instalada nas proximidades do mercado, uns poucos em lugares mais afastados. De modo que, se algum de vós tratar como malfeitores os que vêm ao meu local, evidentemente fará o mesmo com os que frequentam os demais artífices; e, se o faz com esses, tratará como malfeitores todos os atenienses. Pois todos vós tendes o costume de passar e entrar aqui e acolá. 


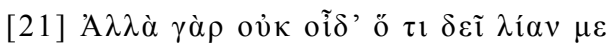

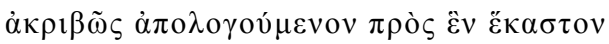

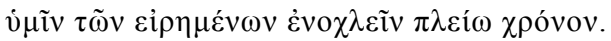

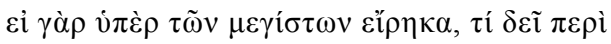

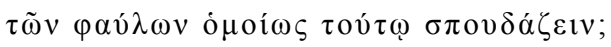

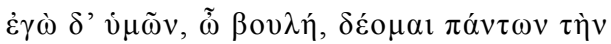
$\alpha$

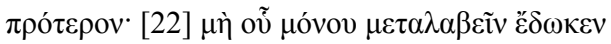

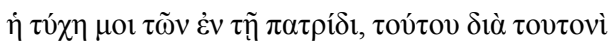

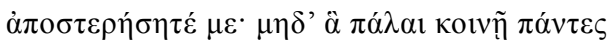

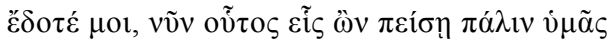

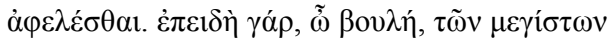

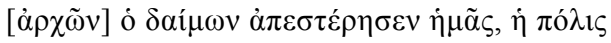

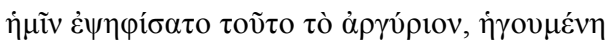

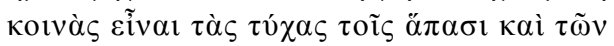

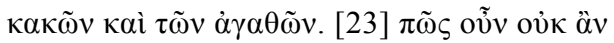

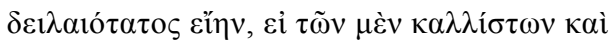

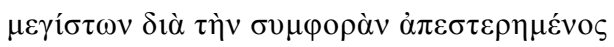

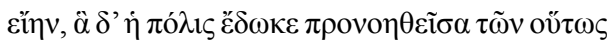

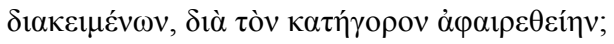

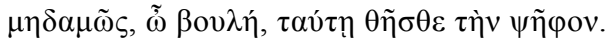

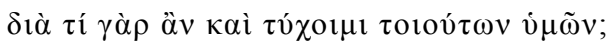

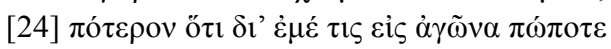

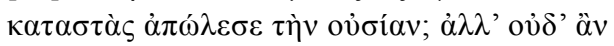

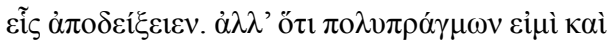

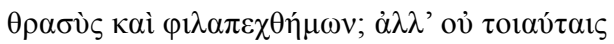

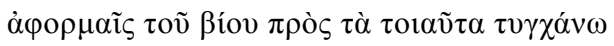

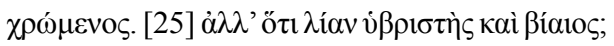

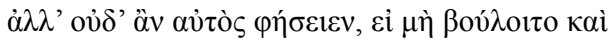

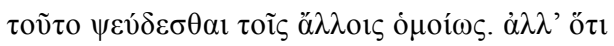

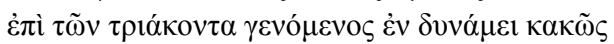

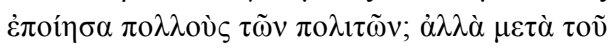

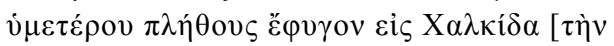

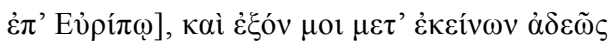

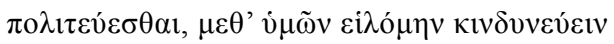

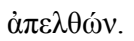

[21] Mas não vejo razão em vos aborrecer por mais tempo, apresentando uma defesa excessivamente detalhada para cada uma das coisas ditas por meu adversário. Pois, se eu já me pronunciei sobre os pontos principais, qual a necessidade de levar a sério, igual a esse homem, assuntos sem importância? Eu, por outro lado, membros do Conselho, peço a todos vós que mantenhais a meu respeito a mesma opinião de antes. [22] Não me priveis, por causa desse homem, do único benefício que a fortuna consentiu que eu compartilhasse dentre aqueles dispensados pela pátria, nem permiti que esse homem, sendo apenas um, vos persuada a me tirar o que todos vós em comum me concedestes. Pois, membros do Conselho, porque o deus nos privou das maiores magistraturas, a cidade votou em nosso favor essa pensão, crendo que a sorte, tanto a boa quanto a má, é comum a todos. [23] Como então eu não seria o mais miserável dentre os homens, se, tendo já sido privado por minha desgraça dos mais nobres e importantes [bens], também fosse despojado por meu acusador dos bens que a cidade concedeu a homens que possuem uma disposição semelhante à minha? De modo algum, membros do Conselho, aprovai tal disposição! Pois por que motivo eu vos encontraria assim dispostos quanto a mim? [24] Acaso porque alguém alguma vez, por minha causa, se envolveu em um litígio e perdeu sua fortuna? Ninguém conseguiria mostrar isso. Acaso porque sou intrigante, petulante e querelante? Acontece que eu não tenho meios de vida para sustentar tal comportamento. [25] Acaso porque sou demasiado insolente e violento? Nem meu próprio acusador poderia afirmá-lo, se não quisesse mentir nesse ponto, como no restante de seu discurso. Acaso porque, durante o governo dos trinta, ${ }^{28}$ ascendi ao poder e fiz mal a muitos cidadãos? Mas, como a maioria dentre vós, fugi para Cálcis, sobre o Euripo, ${ }^{29}$ e, mesmo me sendo possível viver sem medo entre aqueles, preferi arriscar a fuga convosco.

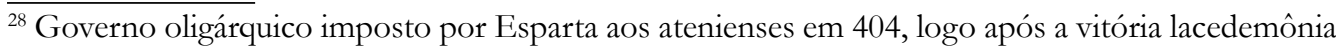
da Guerra do Peloponeso. O governo durou oito meses, sendo deposto por um grupo de cidadãos, que restituíram a democracia à pólis.

${ }^{29}$ Mais de uma cidade na antiga Hélade chamava-se Cálcis, por isso a menção ao rio Euripo, o que situa a referência geográfica na Eubeia.
} 


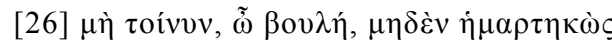

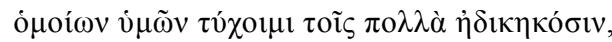

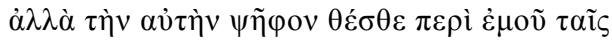

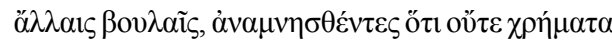

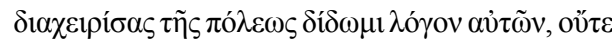

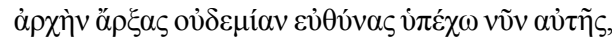

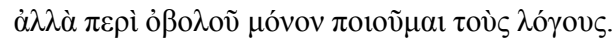

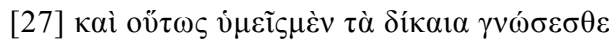

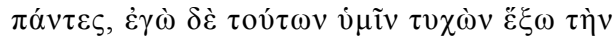

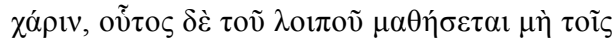

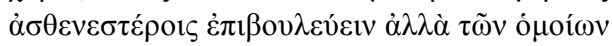

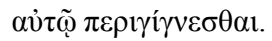

[26] Possa eu então, membros do Conselho, estando isento de qualquer falta, não ser tratado por vós como os que cometeram muitos crimes, mas votai do mesmo modo que os outros Conselhos, tendo na memória que pronuncio esse discurso sem nunca ter cuidado dos fundos da cidade, tampouco estou submetido a um processo de prestação de contas, uma vez que não exerci uma magistratura, mas reclamo com minha fala apenas um óbolo. [27] $\mathrm{E}$ assim todos vós julgareis com justiça, e eu, se obtiver esse resultado, vos serei grato, enquanto que meu acusador aprenderá a, no futuro, não perseguir os mais fracos que ele, mas a investir contra os que lhe são semelhantes.

\section{REFERÊNCIAS}

CHRIST, M. R. Liturgy Avoidance and Antidosis in Classical Athens. Transactions of the American Philological Association, v. 120, p. 147-169, 1990.

DOVER, K. J. Lysias and the Corpus Lysiacum. Berkeley: University of California Press, 1968.

FUHR, K. Observationes in oratores atticos. Bonnae, 1877.

GAGARIN, M. Probability and persuasion: Plato and early Greek rhetoric. In: WORTHINGTON, I. Persuasion: Greek rhetoric in action. London; New York: Routledge, 1994. p. 46-68.

HANSEN, M. H. La Démocratie athénienne à l'époque de Démosthène. Paris: Tallandier, 2009.

LYSIAE Orationes cum fragmentis. Edidit breuique adnotatione critica instruxit Christopher Carey. Oxonii: E typographeo Clarendoniano, 2007.

LYSIAS. Discours vol. II. Texte établi et traduit par M. Bizos et L. Gernet. Paris: Les Belles Lettres, 1926.

LYSIAS. Discours I, XII, XXIV, XXXII. Texte établi par Louis Gernet et Marcel Bizos. Introduction, traduction et commentaire par Pierre Chiron. Paris: Les Belles Lettres, 2015.

SAUPPE, H. Ausgewäblte Schriften. Berlin, 1896.

SCHEIBE, C. Lysiae Orationes. 2. ed. Lipsiae, 1855.

USHER, S. Greek Oratory: Tradition and Originality. Oxford: Oxford University Press, 1999. 